\title{
Two new species of Antarctic gorgonians (Octocorallia: Primnoidae) with a redescription of Thouarella laxa Versluys, 1906
}

\author{
Rebeca Zapata-Guardiola • Pablo J. López-González
}

Received: 1 April 2009/Revised: 21 September 2009/Accepted: 8 October 2009/Published online: 24 October 2009

(C) Springer-Verlag and AWI 2009

\begin{abstract}
Two new species of the genus Thouarella from Antarctic waters are described and illustrated from material collected on the Polarstern cruises ANT XVII/3 (EASIZ III), ANT XIX/5 (LAMPOS) and ANT XXI/2 (BENDEX). On the one hand, Thouarella viridis sp. nov. is placed in the subgenus Epithouarella due to the characteristic ornamentation of its marginal scales (the previously most recent species in this group was included by Kükenthal in Zool Anz 33(1): 9-20, 1908). On the other hand, Thouarella minuta sp. nov. is included in subgenus Thouarella among the 14 species currently recognised, the main distinct feature being tiny polyps. Furthermore, a complete redescription is given of Thouarella laxa Versluys, 1906. Using the new technology available nowadays, such as images obtained with SEM, we provide accurate images of the polyps and sclerites. In addition, as a result of this study, $T$. laxa and its closest congener T. tydemani Versluys, 1906 are maintained as separate species, mainly due to their internal sculpture of body and coenenchymal scales.
\end{abstract}

Keywords Cnidaria $\cdot$ Octocorallia $\cdot$ Primnoidae $\cdot$ Antarctica $\cdot$ Thouarella $\cdot$ New species

Communicated by P. Funch.

R. Zapata-Guardiola $(\bowtie)$ · P. J. López-González

Departamento de Fisiología y Zoología, Facultad de Biología, Universidad de Sevilla, Reina Mercedes 6, 41012 Sevilla, Spain e-mail: rebzapgua@alum.us.es

P. J. López-González

e-mail: pjlopez@us.es

\section{Introduction}

Among the gorgonian families, Primnoidae is one of the richest in genera and species (Bayer 1980, 1981, 1988, 1998). This family is present in both polar waters, north and south, and in deep waters at temperate latitudes (Bayer 1996b), dominating, together with the family Isididae, the high latitudes of the Southern Hemisphere (Bayer 1996a, b, 1998; Alderslade 1998; López-González and Gili 2002). According to Cairns and Bayer (2009), 36 genera with 233 species are currently recognised for Primnoidae, with Thouarella Gray, 1870 being one of the most speciose primnoid genera (Kükenthal 1924; Cairns 2006; Cairns and Bayer 2009) represented in Antarctic and subantarctic waters. According to the most recent contribution giving a generic revision of, and phylogenetic approach to, the Primnoidae (Cairns and Bayer 2009), at least 29 species of Thouarella could be considered valid, several of them in need of revision. Thouarella species are currently organised into four subgenera, Euthouarella Kükenthal, 1915, Epithouarella Kükenthal, 1915, Thouarella Gray, 1870 and Diplocalyptra Kinoshita, 1908 (see Kükenthal 1915; Cairns and Bayer 2009). The main characters used in the identification of the different subgenera are those related to the ornamentation of marginal scales, the arrangement of polyps and the branching pattern of colonies.

During the Antarctic Polarstern cruises ANT XVII/3, ANT XIX/5 and ANT XXI/2, a significant number of Primnoidae specimens were collected, among this material, a number of specimens belonged to the genus Thouarella. The study of a set of these colonies allows us to propose two new species belonging to two of the four recognised subgenera. With these new species, we increase the knowledge of Antarctic diversity and also the variability in colours and polyp sizes previously known in the genus. 
An important task in the revision of a large amount of material from many recent international sampling efforts is obviously the identification of the species collected. This work is directly related to the production of reports and information on biodiversity at different geographic scales. One of the main problems in this taxonomic work is the difficulty in recognising species described in the early history of systematic taxonomy, especially when few characters were described, discussed or illustrated. For this reason, an important effort should be made to redescribe old species under the current descriptive formats, revising the true recognisable distribution and, when possible, relationships with the closest congeners. Recently, we have had the opportunity to consult a fragment of the type material of Thouarella laxa Versluys, 1906. This species was also reported by Kükenthal and Grozawsky (1908), and all subsequent references of this species are based on those old reports. Thus, an additional objective of the present paper is the redescription of Thouarella laxa, based on all known material, with special reference to polyp morphology and sclerite variability. The affinities between $T$. laxa and its closest congener T. tydemani Versluys, 1906 are also discussed.

\section{Materials and methods}

The material of Thouarella laxa here examined came from different European museums which kindly send us part of their specimens for SEM examination of polyp morphology and sclerite variability. The holotype is deposited in the Zoological Museum of Amsterdam (ZMA), The Netherlands. The remaining material belonged to the Doflein collection and is deposited in The Bavarian State Collection of Zoology, Munich (ZSM),
Germany. For the purposes of comparison, the following material deposited at the Zoological Museum of Amsterdam (ZMA) has also been examined: Thouarella tydemani Versluys, 1906. (ZMA, COEL09256) Holotype: Siboga Expedition, stn 297, 10³9'S, $123^{\circ} 40^{\prime} \mathrm{E}$, Lesser Sunda Islands, Timor Sea, Indonesia, $520 \mathrm{~m}$ depth, 27 January 1900, three slides.

The material studied, concerning the new species, was collected on the $R / V$ Polarstern cruises ANT XVII/3 (EASIZ III, Ecology of the Antarctic Sea Ice Zone, 18 March to 11 May 2000), ANT XIX/5 (LAMPOS, Latin American Polarstern Study, 3 April to 5 May 2002), ANT XXI/2 (BENDEX, BENthos Disturbance EXperiment, 17 November 2003-18 January 2004) sponsored by the Alfred Wegener Institut für Polar- und Meeresforschung (Bremerhaven) under the auspices of the SCAR (Scientific Committee for Antarctic Research). Octocoral colonies were collected using an Agassiz trawl or a bottom trawl along South Georgia Ridge (Scottia Arc) and Austasen (eastern Weddell Sea) (Fig. 1). The octocorals were fixed in buffered formalin $10 \%$ and then transferred to ethanol $70 \%$. Fragments from different parts of the colonies were prepared for study by SEM employing the usual methodology previously described by various authors (e.g. Bayer and Stefani 1988; Alderslade 1998), and permanent mounts were made for light microscopy observation. All sclerite size measurements and illustrations are from the holotypes. The colony and sclerite terminology herein mainly follow Bayer et al. (1983). The material studied has been deposited at the Zoologisches Institut und Zoologisches Museum, Hamburg, Germany (ZIZMH); the National Museum of Natural History, Smithsonian Institution, Washington, D.C. (USNM) and in the octocoral reference collection of the research group "Biodiversidad y Ecología de Invertebrados Marinos" of the University of Seville (CRO).
Fig. 1 Known distribution of Antarctic Thouarella species described in this paper: triangle, Thouarella viridis sp. nov.; square, Thouarella minuta sp. nov. Solid symbols represent the respective localities where the holotypes were collected

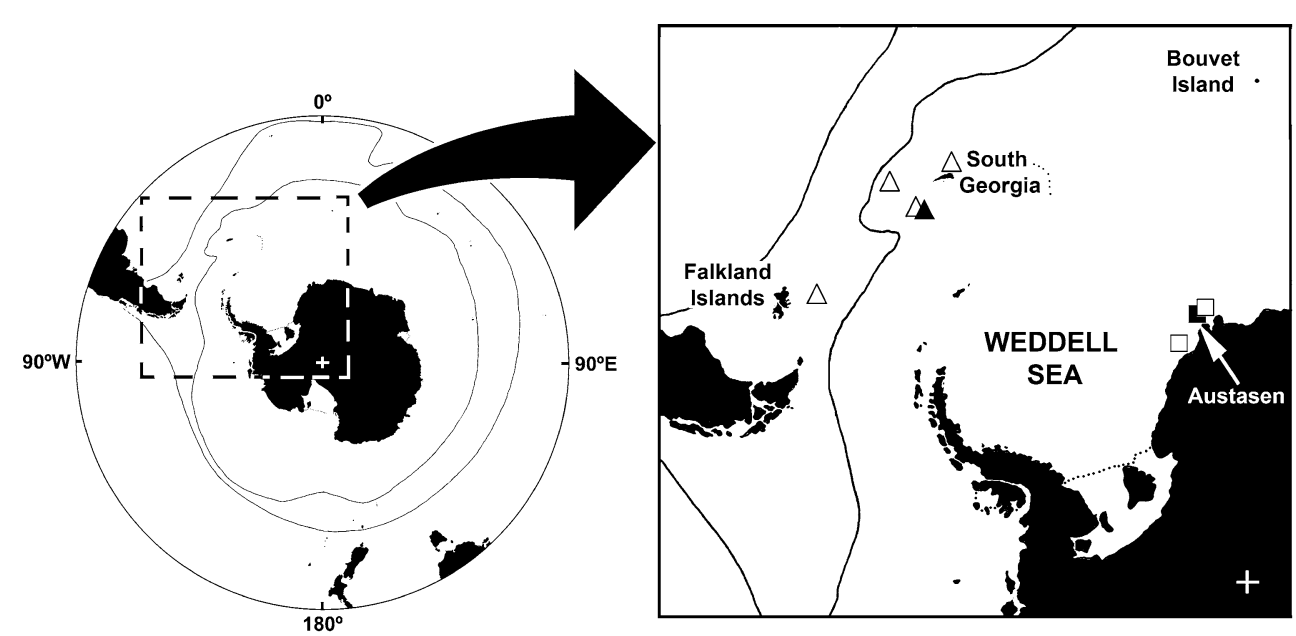




\section{Results}

Family Primnoidae Gray, 1858

Genus Thouarella Gray, 1870

Diagnosis

Primnoidae commonly with a bottlebrush colony shape and simple or ramified branchlets with also fan-shaped colonies. Polyps cylindrical to club shaped, upward or almost perpendicular to stem, straight or adaxially incurved and arranged single or in whorls. Opercular scales usually keeled, eight in number and arranged in two alternate cycles. Marginal scales also eight in number, alternating in two cycles, with a keel folding over operculars in an indented way. Adaxial body scales often reduced.

Subgenus Euthouarella Kükenthal, 1915

Diagnosis

Thouarella with polyps placed in pairs or whorls. Marginal scales bearing thorns.

Thouarella (Euthouarella) laxa Versluys, 1906 (Figs. 2, 3,4 , and 5)

? Hookerella pulchella Gray, 1870: 45.

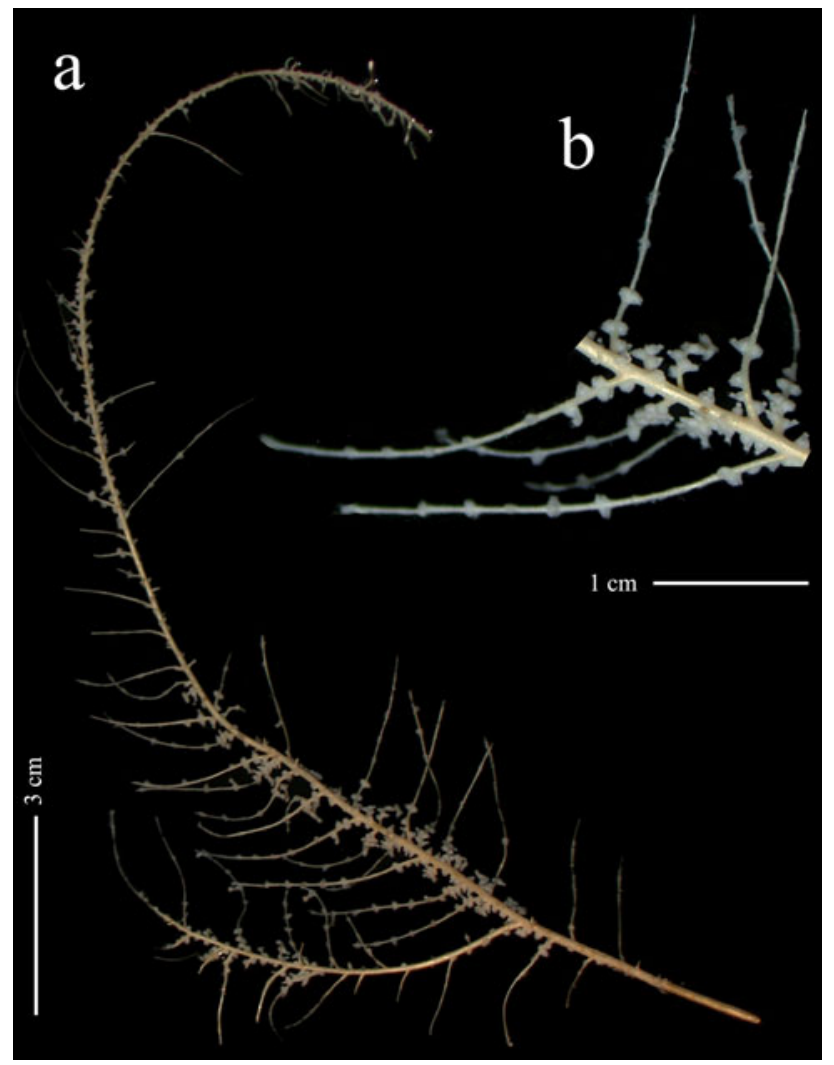

Fig. 2 Thouarella laxa Versluys, 1906, holotype (COEL03576): a whole colony; $\mathbf{b}$ detail of branchlets
Thouarella laxa Versluys, 1906: 30-32, pl. 1, fig. 5; pl. 3, fig. 8; text figs. 28-33.-Kükenthal and Grozawsky, 1908: $36-37$, pl. 2, fig. 13 .

Thouarella (Euthouarella) laxa, Kükenthal, 1915: 150.Kükenthal, 1919: 417.-Kükenthal, 1924: 293-294, text fig. 164.-Cairns and Bayer, 2009: 28 (in list).

\section{Examined material}

Holotype: ZMA (COEL 03576), Siboga Expedition, stn 88, $0^{\circ} 34.6^{\prime} \mathrm{N}, 119^{\circ} 8.5^{\prime} \mathrm{E}$, Strait of Makassar, Sulawesi, Indonesia, 1,301 m depth, 20 June 1899. Additional material: ZSM (20080407), ZSM (20080408) and ZSM (20080409), Steam Vessel “Zuso Maru”, Sagami Bay, Okinose, 300$700 \mathrm{~m}$ depth, 8-15 November 1904, Doflein Collection 1904-1905.

Description of the holotype

Fragment examined (Fig. 2a) $22 \mathrm{~cm}$ in length, in one plane, feather-like, with simple branchlets up to $22 \mathrm{~mm}$ in length (Fig. 2b). One main lateral branch of $70 \mathrm{~mm}$ in length also bearing simple branchlets up to $28 \mathrm{~mm}$ in length. Axis ochre coloured, slender and graceful.

Polyps perpendicular to branchlets (Fig. 3b), in pairs, 4 pairs per $\mathrm{cm}$. Polyps singly placed on stem. Polyps (Fig. 3) cylindrical, funnel shaped distally, about $1.2-1.4 \mathrm{~mm}$ in height and about $0.8 \mathrm{~mm}$ in diameter in their basal portion; polyp diameter reduced at its mid length, wider distally. Operculum small (Fig. 3c), delicate and easily breakable. Distal part of the polyp directed inwards towards the branchlet (Fig. 3b, d). Polyps with 7 longitudinal rows of scales, 6-7 transverse rows of scales on each longitudinal abaxial row overlapping one another (Fig. 3a).

Opercular scales, arranged in 2 alternate cycles of 4 scales each, 0.17-0.49 $\mathrm{mm} \times 0.07-0.27 \mathrm{~mm}$. Inner cycle (Fig. 4a) small, narrow and lancet shaped; outer cycle (Fig. 4b) large, concave with blunt and square tip. Inner proximal surface tuberculate, inner distal surface smooth and lacking a keel. Outer proximal surface with few granules and distal outer surface smooth. Basal margin with digitate processes, free margin smooth.

Marginal scales (Fig. 4c), $0.53-0.81 \mathrm{~mm} \times 0.24$ $0.40 \mathrm{~mm}$, arranged in 2 alternate cycles of 4 scales each, more or less triangular with long ridged spine up to $2 / 3$ of total scale length. Outer surface smooth, $1 / 3$ of inner proximal surface densely tuberculate, remaining base-lateral surface of spine smooth, granulated or ridged. Basal margin with digitate processes, free margin serrated.

Body scales (Fig 4d) round and more or less oval, 0.26$0.64 \mathrm{~mm}$ in diameter. Outer surface smooth or granulated, inner surface tuberculate and with inner face of the distal 
Fig. 3 Thouarella laxa Versluys, 1906, holotype (COEL03576): a polyp on abaxial view; b polyp on lateral adaxial view; c polyp on oral view; d polyp on lateral view. Abbreviations: $o$ opercular scales, $m$ marginal scales
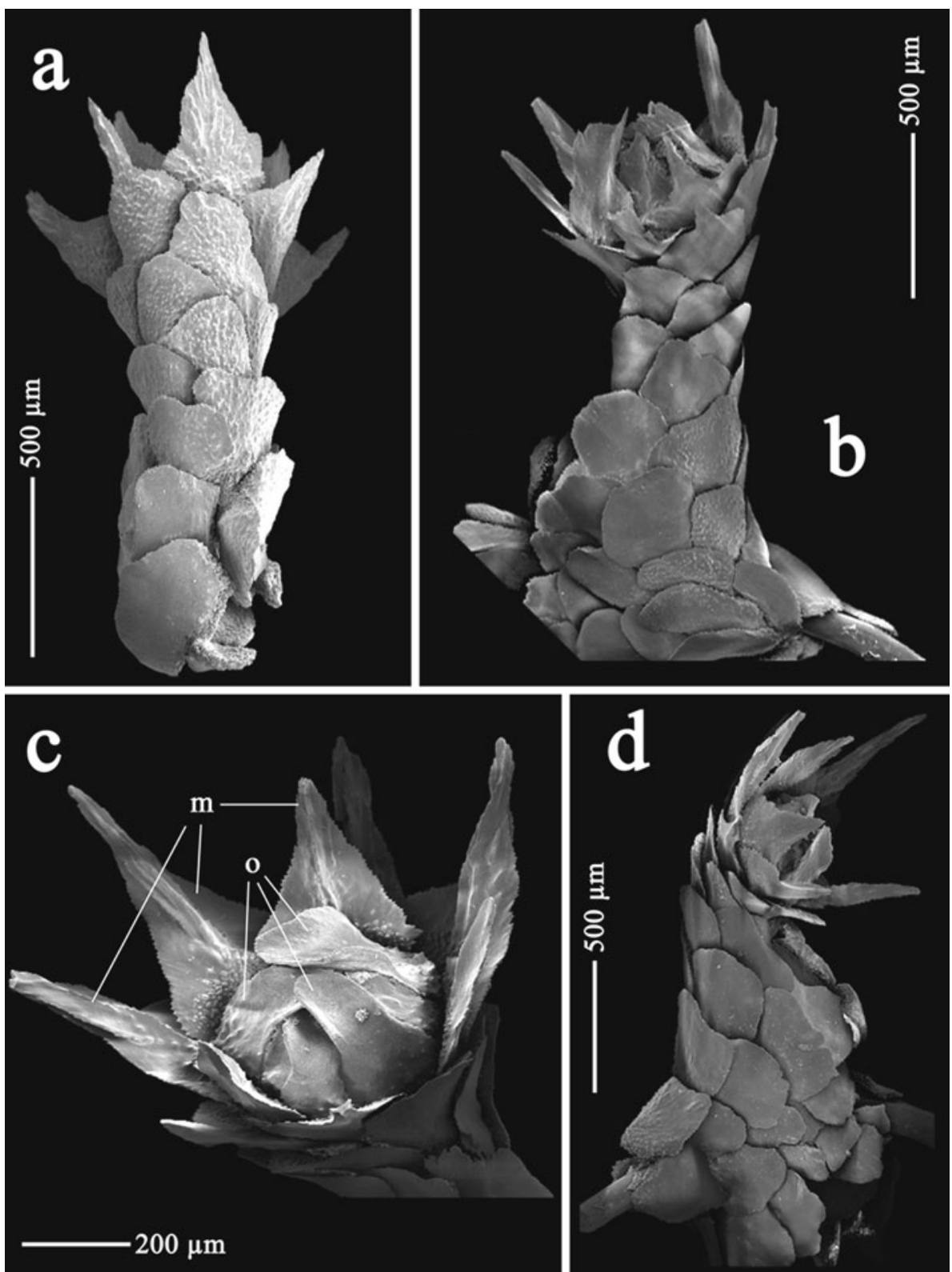

margin smooth. Basal margin with digitate processes, free margin serrated.

Coenenchyme scales (Fig. 5) similar in shape to body scales but smaller and $0.15-0.45 \mathrm{~mm}$ in maximum length.

\section{Variability}

Material examined is comprised of small colony fragments of 2.6-4 cm in length, presumable side branches belong to larger colonies. These fragments show a similar branching to the holotype, having small branchlets from 0.75 to $2.8 \mathrm{~cm}$ in length. The polyps are 1.2 to $1.7 \mathrm{~cm}$ in height and are arranged in whorls of two or three on branchlets; being singly placed on stems. The number of whorls per centimetre varies from 4 to 7 . The sclerites from the polyps are as in the holotype, varying slightly in sizes: opercular scales, $0.16-0.55 \mathrm{~mm} \times 0.05-0.27 \mathrm{~mm}$; marginal scales, $0.36-0.81 \mathrm{~mm} \times 0.14-0.4 \mathrm{~mm}$; and body scales, 0.24 $0.64 \mathrm{~mm}$ in maximum length.

Geographic and bathymetrical distribution

At present, Thouarella laxa is known from the West Pacific Ocean, from Indonesia to Japan. The bathymetric distribution of T. laxa varies between 400 and 1,301 m.

\section{Remarks}

Thouarella laxa was described by Versluys (1906) in his primnoid monograph based on the material collected by the 


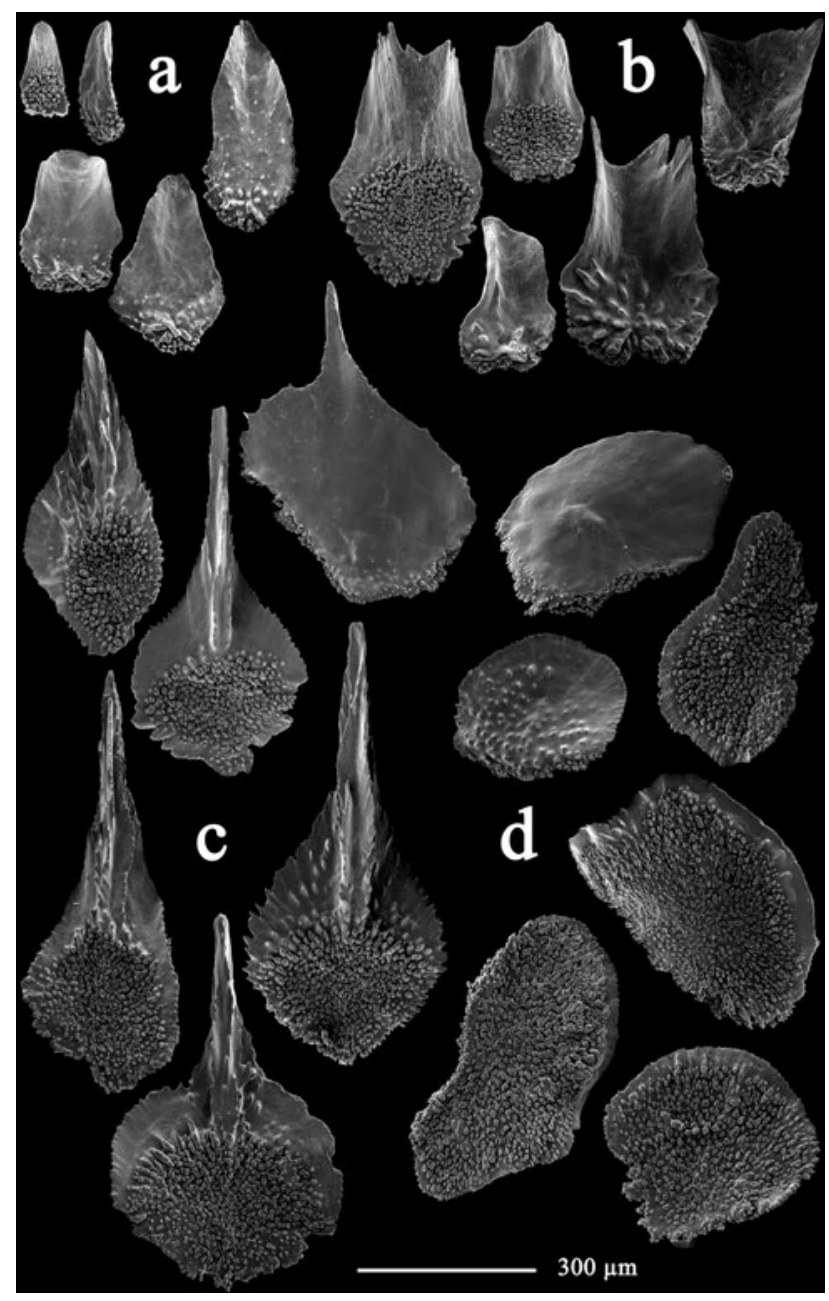

Fig. 4 Thouarella laxa Versluys, 1906, holotype (COEL03576): Opercular scales from inner (a) and outer (b) alternate cycles; c marginal scales; $\mathbf{d}$ body scales

Siboga Expedition. In the same work, Versluys also described a similar species, T. tydemani. In the words of Versluys "ist sie unschwer zu unterscheiden von der nächst zu beschreibenden Art diese Genus, der T. tydemani, vomit ihre Polypen grosse Ähnlichkeit besitzen”. Because of that, it is reasonable to discuss here the taxonomic characters of
T. laxa with those available from the original description of T. tydemani, and the current existing type material (three slides mounted in Canadian balsam, showing two branches, polyps and coenenchymal scales of the stem). No colony or fragments from the type of this latter species are currently present at the ZMA (Dr. R. van Soest, personnel communication), and the material seems to have been lost.

Both species have very similar polyps but were differentiated by Versluys due to their general appearance, these polyps being wider and more robust in Thouarella tydemani than in T. laxa, which also shows differences in sclerites. In addition, T. tydemani has body scales with the free margin more curved and marginal scales with slightly larger spines (after Versluys, up to $0.45-0.50 \mathrm{~mm}$ in total length of the spine, while this measurement could be about $0.37 \mathrm{~mm}$ in $T$. laxa). However, in the examined type material, we have observed a variation range for this character between 0.26 and $0.54 \mathrm{~mm}$.

After the study of the holotype of Thouarella laxa and additional material from Doflein's collection currently held at the ZSM, the initial ranges of variability observed by Versluys have been increased. The examination of these specimens allows us to give a revised diagnostic description of the known material recognised for this species. For T. tydemani, there is only the original description, and no more reports have been published based on newly collected specimens. Based on the original description of $T$. tydemani, this species does not show any distinctive character to distinguish it from $T$. laxa. The variability ranges concerning the size of branches, the number of whorls per centimetre, the number of polyps per whorls, the size of polyps, the number of sclerites in the longitudinal abaxial row and also the description of the sclerites are not different from those in T. laxa variability. Versluys (1906: 34) mentions the distinct coenenchymal sclerites of the main stem of $T$. tydemani. The sclerites in this area are usually 0.25 to $0.35 \mathrm{~mm}$. However, they can exceptionally reach to more than $0.7 \mathrm{~mm}$. In the material of T. laxa here examined, the range of sizes for the coenenchymal sclerites clearly overlaps those mentioned by Versluys for
Fig. 5 Thouarella laxa Versluys, 1906, holotype (COEL03576): Coenenchymal scales

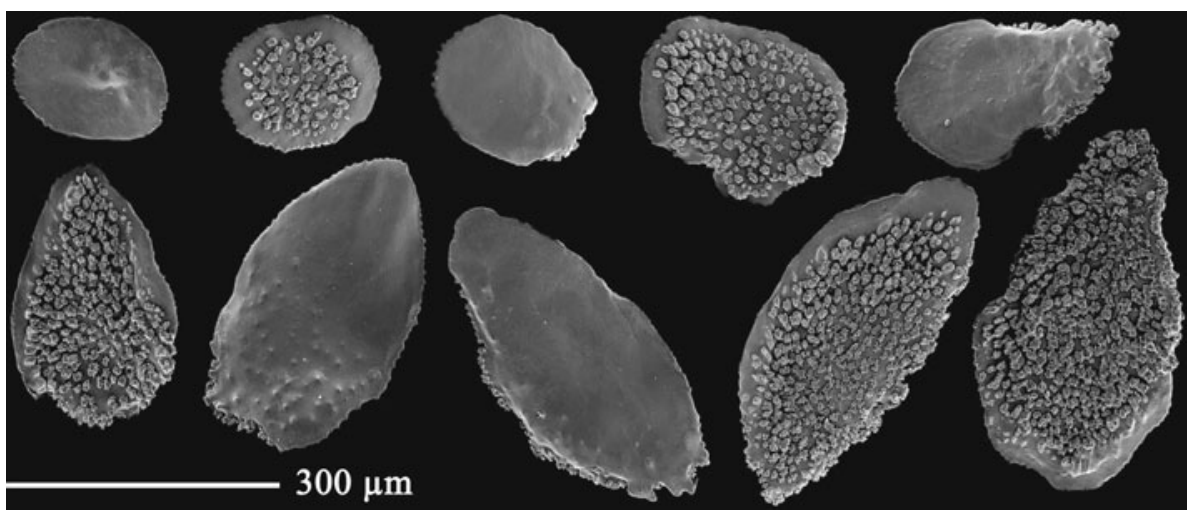


Fig. 6 Thouarella tydemani Versluys, 1906, holotype (COEL09256): a detail of branchlets; b coenechymal scales of branchlet; c body scales with smooth margin; d body scale with ridged margin; e-f coenenchymal scales of main stem
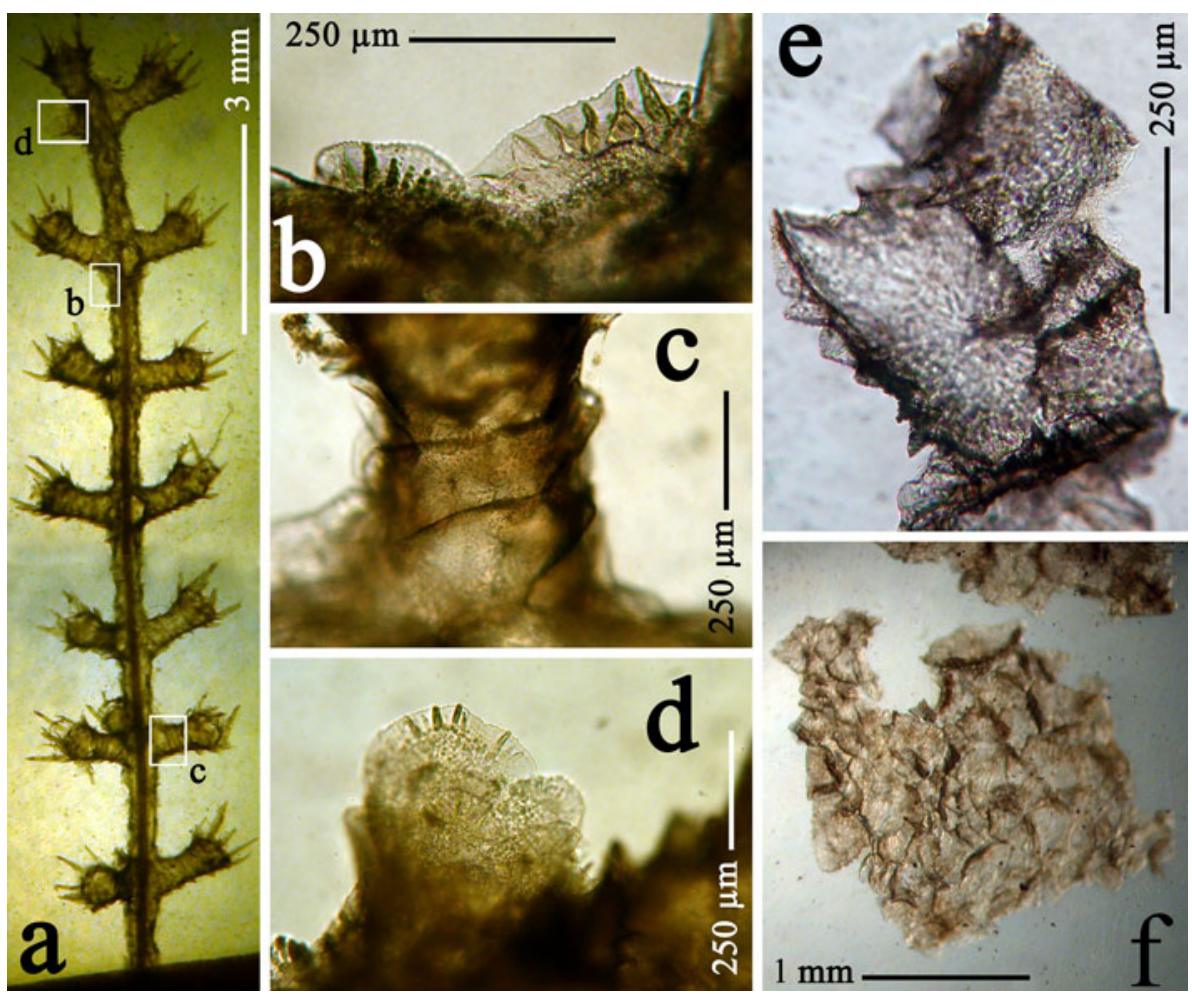

T. tydemani. In addition, this character, especially when measured at the main stem, is possibly not one of the best to differentiate two primnoid species, because it can be influenced by the age of the colony, the presence of symbionts and the growth conditions. However, after the study of the three slides of the type specimen of Thouarella tydemani, the internal ornamentation of the coenenchymal scales as well as some body scales consists of short marginal ridges (Fig. 6b, d), absent in $T$. laxa, where these scales show a smooth inner surface. Thus, the inner ornamentation of these scales could be used as a taxonomic character to distinguish both species.

Although Thouarella laxa and T. tydemani are very close related, the existing type material of $T$. tydemani cannot be examined (a few slides in Canada balsam) using the comparative techniques (SEM) currently in use for the taxonomy of this family. Because of this, the redescription of this species is highly recommended after the location of recognisable additional material.

Subgenus Epithouarella Kükenthal, 1915

\section{Diagnosis}

Thouarella with polyps placed singly. Marginal scales pointed, ridged or with spinose projections, without bearing real thorns.

Thouarella (Epithouarella) viridis sp. nov. (Figs. 7, 8, 9, and 10)

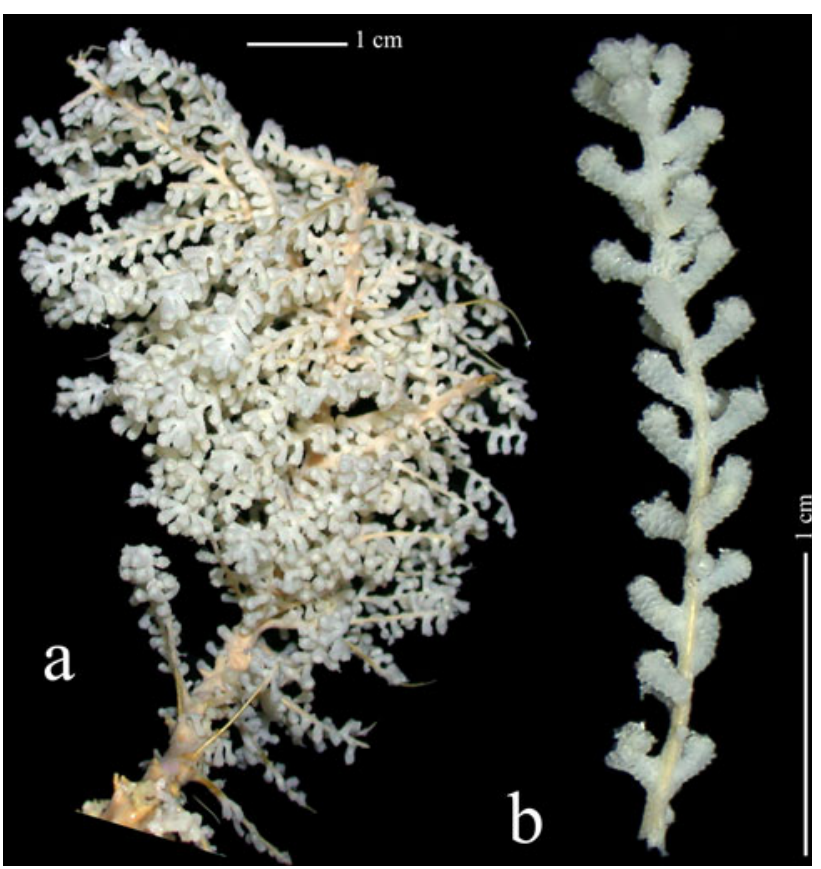

Fig. 7 Thouarella viridis sp. nov, holotype ZIZMH C11744: a whole colony; b detail of branchlet

Examined material

Holotype: ZIZMH C11744, ANT XIX/5, stn PS61/164-01, $53^{\circ} 23.80^{\prime} \mathrm{S}, \quad 42^{\circ} 42.03^{\prime} \mathrm{W}$, west of South Georgia, 

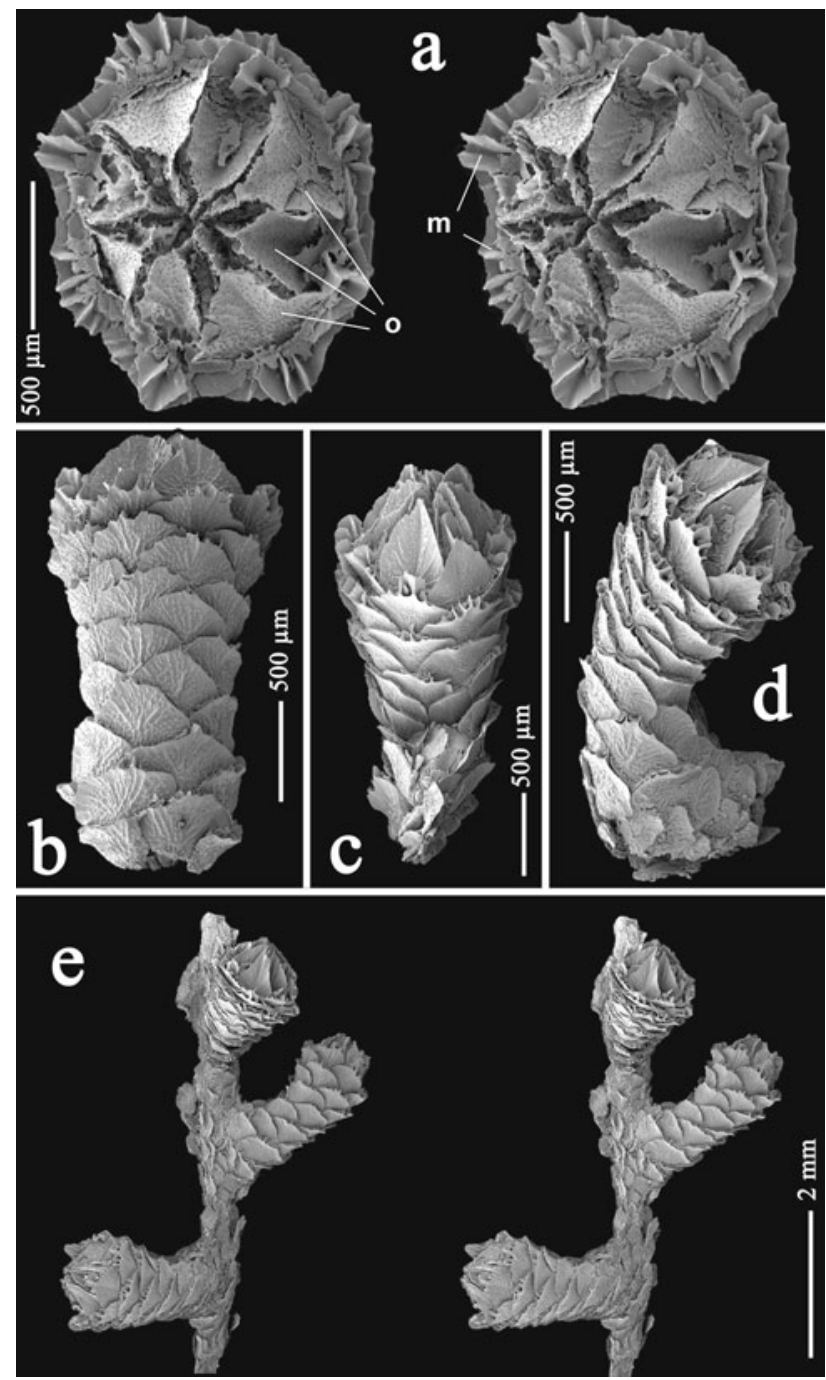

Fig. 8 Thouarella viridis sp. nov, holotype ZIZMH C11744: a polyp in oral view, stereo pair; b polyp in abaxial view; c polyp in adaxial view; d polyp in lateral view; e detail of branchlets, stereo pair. Abbreviations: $o$ opercular scales; $m$ marginal scales

Antarctica, 312.5-321.6 m depth, 9 April 2002. Paratypes: ZIZMH C11745, with the same sampling data as the holotype, four fragments; CRO-0038, ANT XIX/5, stn PS61/150-01, $54^{\circ} 30.22^{\prime} \mathrm{S} 56^{\circ} 08.20^{\prime} \mathrm{W}$, south east of Falkland Islands, Antarctica, 286.3-291.6 m depth, 6 April 2002, 1 fragmented colony; USNM 1128949 and CRO-

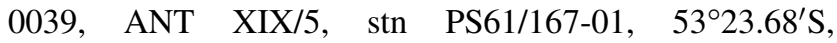
$42^{\circ} 42.23^{\prime} \mathrm{W}$, west of South Georgia, Antarctica, 306.0 $342.7 \mathrm{~m}$ depth, 9 April 2002, two fragments and one colony and various fragments respectively; CRO-0040, ANT $\mathrm{XIX} / 5$, stn PS61/174-01, $54^{\circ} 24.47^{\prime} \mathrm{S}, 35^{\circ} 36.81^{\prime} \mathrm{W}$, north east of South Georgia, Antarctica, 278.3-279.8 m depth, 11 April 2002, four fragments; CRO-0041, ANT XIX/5, stn PS61/182-01, $54^{\circ} 27.63^{\prime} \mathrm{S}, 35^{\circ} 41.33^{\prime} \mathrm{W}$, north east of South Georgia, Antarctica, 249.3-256.0 m depth, 12 April 2002, two fragments.

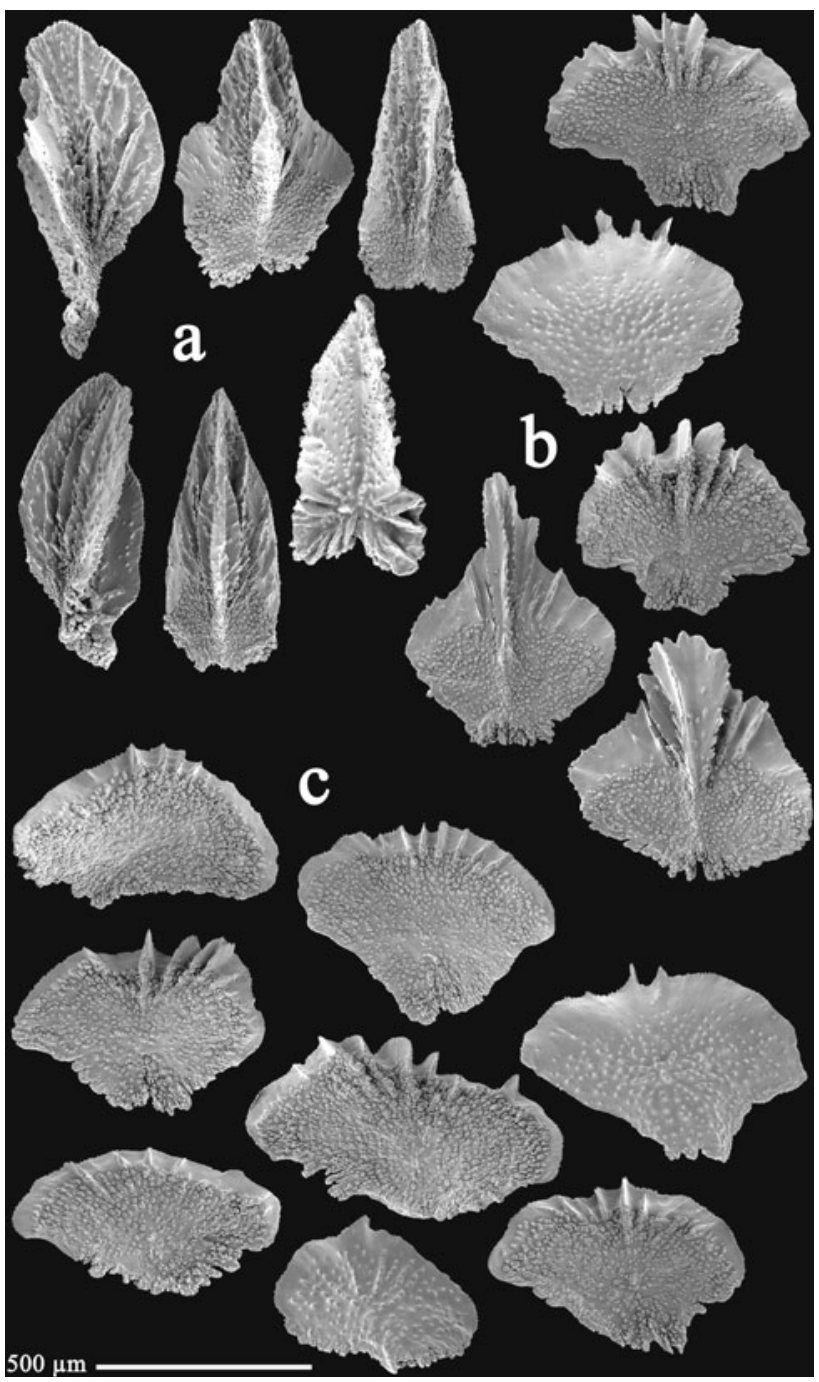

Fig. 9 Thouarella viridis sp. nov., holotype ZIZMH C11744: a opercular scales; b marginal scales; c body scales

Description of the holotype

Fragment of a larger colony (Fig. 7a) of $10.2 \mathrm{~cm}$ in total height and $5.4 \mathrm{~cm}$ in width, with two short lateral branches of 2.3 and $3.5 \mathrm{~cm}$ in length. Main stem and lateral branches with simple branchlets (Fig. 7b), occasionally ramified up to two orders, in a bottlebrush branching pattern. Branchlets up to $3 \mathrm{~cm}$ in length, from seven to eight branchlets per $\mathrm{cm}$. Living specimens green in colour, preserved material whitish. Axis ochre in colour, stiff and thick, basal axis diameter of $4 \mathrm{~mm}$.

Polyps (Figs. 7b, 8e) straight and directed upward to stem, singly placed, present on main stem, branches and branchlets. Regularly arranged in spirals and more crowded distally, while in the basal portion the polyps are occasionally nearly opposite, with no tendency towards pairs or 
Fig. 10 Thouarella viridis sp. nov., holotype ZIZMH C11744: Coenenchymal scales

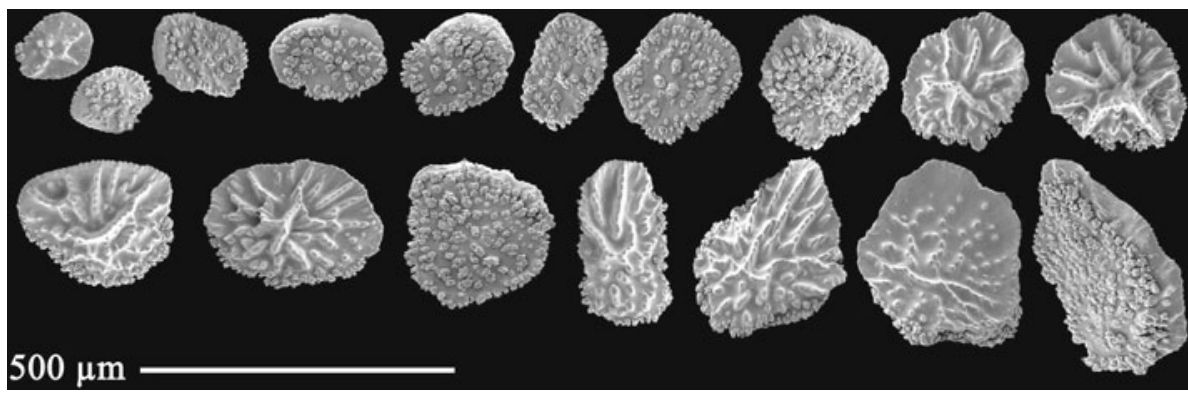

whorls, 14-15 polyps per $\mathrm{cm}$. Polyps relatively elongated, cylindrical to club-shaped distally, with a conical operculum (Figs. 8a-d); about 2.1-2.5 $\mathrm{mm}$ in height and 0.73$0.85 \mathrm{~mm}$ in diameter. Polyp body with 8 longitudinal rows of scales, 6-7 scales on each longitudinal abaxial row (Fig. 8b) overlapping one another and slightly reducing in size basally.

Opercular scales (Fig. 9a) large, eight in number, 0.62$0.78 \mathrm{~mm} \times 0.24-0.42 \mathrm{~mm}$, isosceles shaped with bilobed base and acute tip. Proximal inner surface tuberculate, covering more than one-third of their length. Prominent, strong, apical keel, often bearing additional lateral ridges. Distal inner surface of scale also with longitudinal ridges. Outer surface granulate, with a longitudinal valley corresponding to inner keel. Basal margin with digitate processes, free margin finely serrated.

Eight marginal scales (Fig. 9b) $0.45-0.63 \mathrm{~mm} \times 0.47-$ $0.64 \mathrm{~mm}$, pentagonal shaped. Proximal inner surface tuberculate, covering up to about $80 \%$ of their length of scales with 3-4 short middle ridges and without a spine; other scales with a small blunt spine sculpted by longitudinal ridges have tubercles covering up to half of their length. Lateral inner distal surface smooth, without granules or ridges. Outer surface granulate. Basal margin with digitate processes, free margin finely serrated.

Body scales (Fig. 9c) like marginal scales in shape with tendency to be fan shape, $0.27-0.51 \mathrm{~mm} \times 0.34-0.74 \mathrm{~mm}$, without spines and often decreasing in number and size from distal to basal scales. Adaxials with tendency to be reduced. Inner side with short ridges and up to about $80 \%$ tuberculate.Outer surface granulate. Free margin finely serrated, basal margin with digitate processes.

Coenenchyme scales (Fig. 10) round to oval shaped, $0.13 \mathrm{~mm}-0.36 \mathrm{~mm}$ in maximum length. Inner surface tuberculate, outer surface granulate forming ridges. Margin irregular with warts proximally, and the remainder finely serrated.

\section{Variability}

The general colonial and polyp structure of the paratypes and additional examined material are quite similar to that of the holotype. The branches and branchlets arise from all around the main stem, from seven to nine branchlets per centimetre in number. Sometimes, the colony shows the branchlets bent towards one side of the colony, giving the false impression of being disposed in a plane. The lateral branches can reach up to $9.3 \mathrm{~cm}$ in length, and branchlets up to $4 \mathrm{~cm}$, sometimes ramified up to three orders. The number of polyps per centimetre can vary from 10 to 15 on branchlets. The distribution and form of the sclerites from polyps and coenenchyme are as in the holotype.

Geographic and bathymetrical distribution

At present, Thouarella viridis sp. nov. is only known from South Georgia Island area and south east of Falkland Islands, Antarctica (Fig. 1), between 249 and $342 \mathrm{~m}$ in depth.

\section{Etymology}

The specific epithet viridis comes from one of the most distinctive features shown by this species. When sorting the fresh material collected during the catches, its olive green colour was very evident, while most of the Antarctic primnoid gorgonians vary in colour from whitish or yellowish to orange.

\section{Remarks}

Polyps of Thouarella viridis sp. nov. resemble polyps of the genus Amphilaphis due to the prominent apical keel on the inner surface of the opercular scales. However, the distinct branching pattern and the slight reduction in size of the basal body scales suggest that this species could be better placed among the Thouarella species, where the presence of keels on the inner surface of operculars has also been documented.

According to previous works and the recent generic revision of the family Primnoidae given by Cairns and Bayer (2009), Thouarella viridis sp. nov. is here considered in the subgenus Epithouarella because of the lack of a spine on the marginal scales. In this subgenus, three species 
have been previously recognised: T. crenelata Kükenthal, 1907, T. affinis Wright and Studer, 1889 and T. chilensis Kükenthal, 1908. The former two are present in Antarctic and subantarctic regions.

After the original description for Thouarella crenelata, this species has a high number of sclerites in the abaxial rows of the polyp, from nine to ten, while $T$. viridis sp. nov. only presents six or seven scales. Furthermore, the ornamentation of the marginal scales also shows differences in both species. In $T$. crenelata, the marginal scales (see Kükenthal (1919): fig. 217; Cairns and Bayer (2009): fig. 7k-1) are strongly ornamented on their free margin, with serrated marginal surface and projecting teeth in the middle distal part; the outer surface being ornamented with longitudinal ridges from the nucleus. In T. viridis sp. nov., the marginal scales have an almost flat marginal surface, a smooth (Fig. 9b) or finely serrated margin and three-four prominent ridges on the middle distal part, like short keels; the outer surface being finely granulated, without forming ridges.

Thouarella affinis and $T$. chilensis overlap with $T$. viridis sp. nov. in the number of scales in the longitudinal abaxial row. Kükenthal (1915) distinguished T. affinis and $T$. chilensis by the distinct arrangement of polyps on the branches (possibly branchlets), where T. affinis shows a regular distribution, while $T$. chilensis shows a dense distribution, which attains a cylindrical shape. Concerning this character, $T$. viridis $\mathrm{sp}$. nov. shows a regular distribution of polyps on the branchlets, being close to $T$. affinis.

Thouarella viridis sp. nov. and T. affinis are differentiated by the operculars. In T. affinis, these scales have two lateral teeth, and there is no mention of a strong keel on the inner surface (Wright and Studer 1889: 67-68, pl. 21 fig. 3). In T. viridis sp. nov., this keel is distinctly present in the operculars, lateral teeth being completely absent.

In the case of $T$. chilensis, additional differences with $T$. viridis sp. nov. can be observed in the scales of the polyps. The characteristic large operculars with a strong keel on the inner surface of $T$. viridis sp. nov. contrast with the smaller operculars without keel shown by $T$. chilensis (Kükenthal 1919: 303, text fig. 7). In the same work, Kükenthal described body scales with the free margin finely serrated, while in $T$. viridis sp. nov., these sclerites show a series of short distal ridges (see Fig. 9c).

Subgenus Thouarella Gray, 1870

\section{Diagnosis}

Thouarella with polyps placed singly. Marginal scales bearing thorns.

Thouarella (Thouarella) minuta sp. nov. (Figs. 11, 12, and 13)

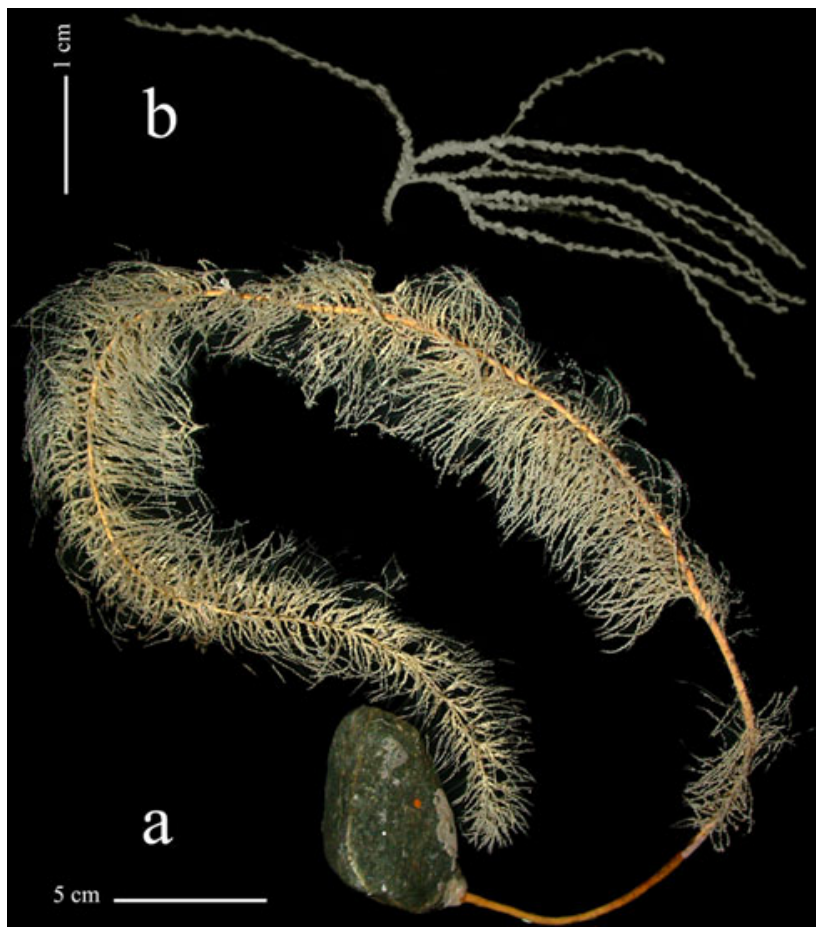

Fig. 11 Thouarella minuta sp. nov., holotype ZIZMH C11742: a whole colony; $\mathbf{b}$ detail of branchlets
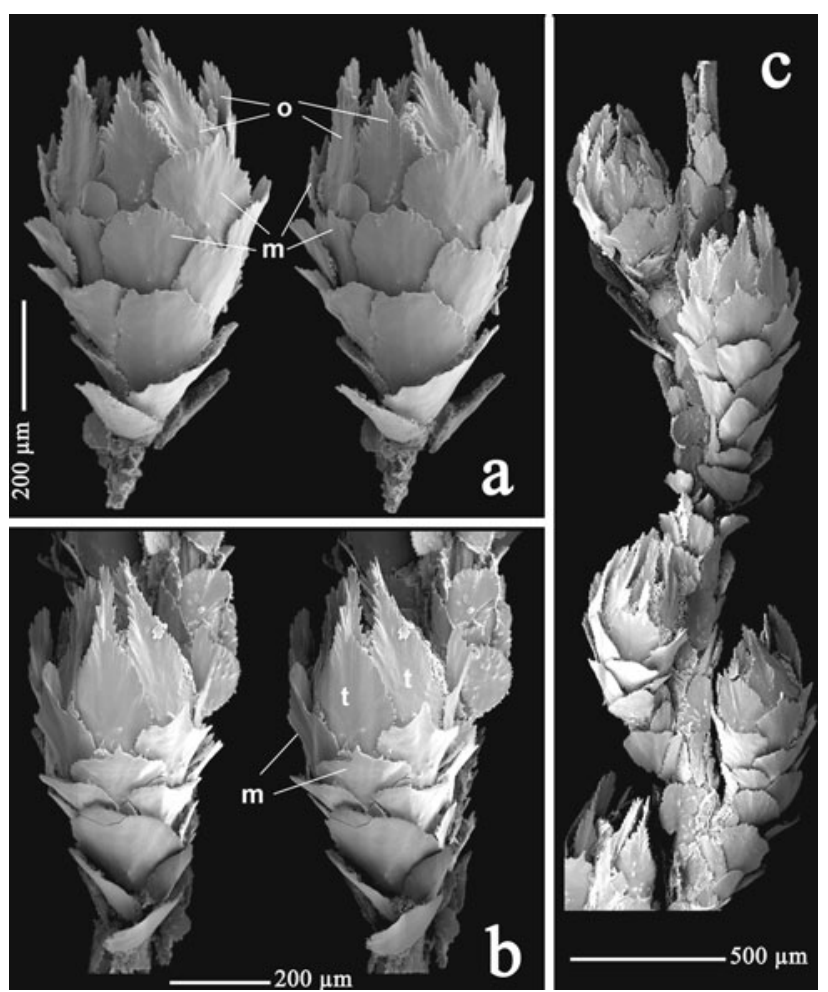

Fig. 12 Thouarella minuta sp. nov., holotype ZIZMH C11742: a polyps in lateral abaxial view, stereo pair; b polyps in abaxial view, stereo pair; c detail of branchlets. Abbreviations: $o$ opercular scales; $m$ marginal scales 


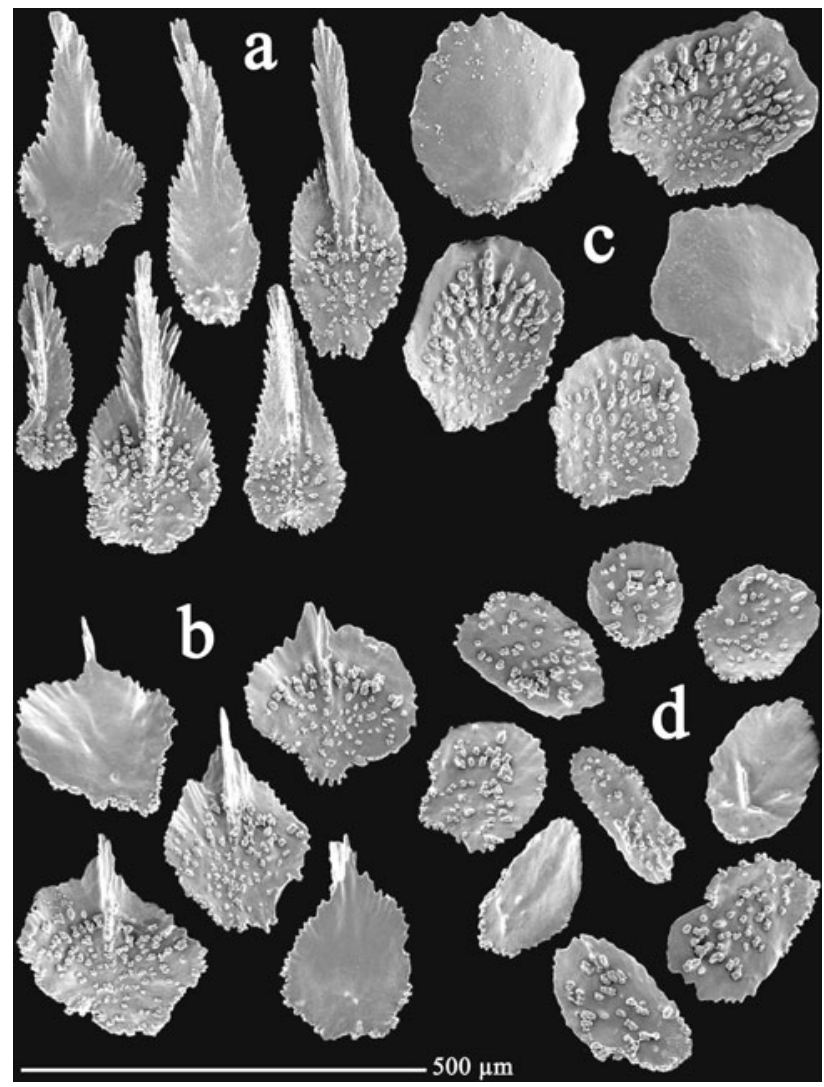

Fig. 13 Thouarella minuta sp. nov., holotype ZIZMH C11742: a opercular scales; b marginal scales; c body scales; d coenenchymal scales

\section{Examined material}

Holotype: ZIZMH C11742, ANT XXI-2, stn PS65-166-01, $70^{\circ} 56.83^{\prime} \mathrm{S}, 10^{\circ} 32.61^{\prime} \mathrm{W}$, Austasen, Antarctica, 253.2338.0 depth, 15 December 2003. Paratypes: ZIZMH C11743, USNM 1128948 and CRO-0042, with the same sampling data as the holotype, five fragmented colonies and one fragment, four colonies and one colony, one broken colony and two naked stems, respectively; CRO-0031, ANT XVII-3, stn $085-01,71^{\circ} 11.30^{\prime} \mathrm{S}, \quad 12^{\circ} 15.40^{\prime} \mathrm{W}$, Austasen, Antarctica, 309-318 m depth, 2 April 2000, two colony fragmented; CRO-0032, ANT XVII-3, stn 119-01, $70^{\circ} 50.40^{\prime} \mathrm{S}, 10^{\circ} 35.20^{\prime} \mathrm{W}$, Austasen, Antarctica, 226-266 depth, 7 April 2000, one colony and two fragments; CRO0033, ANT XXI-2, stn PS65-174-01, 70 56.57'S, $10^{\circ} 31.86^{\prime} \mathrm{W}$, Austasen, Antarctica, 253.2-296.0 m depth, 16 December 2003, four fragmented colonies and two fragments; CRO-0034, ANT XXI-2, stn PS65-175-01, $70^{\circ} 56.52^{\prime} \mathrm{S}, 10^{\circ} 31.78^{\prime} \mathrm{W}$, Austasen, Antarctica, 288.8$337.2 \mathrm{~m}$ depth, 16 December 2003, two colonies without holdfast; CRO-0035, ANT XXI-2, stn PS65-265-01, $70^{\circ} 52.74^{\prime} \mathrm{S}, 10^{\circ} 52.72^{\prime} \mathrm{W}$, Austasen, Antarctica, 285.6$294.8 \mathrm{~m}$ depth, 27 December 2003, four colonies, one of them broken; CRO-0036, ANT XXI-2, stn PS65-274-01, $70^{\circ} 52.16^{\prime} \mathrm{S}, 10^{\circ} 43.69^{\prime} \mathrm{W}$, Austasen, Antarctica, 288.0 $290.8 \mathrm{~m}$ depth, 28 December 2003, one colony and four fragmented colonies; CRO-0037, ANT XXI-2, stn PS65292-01, $72^{\circ} 51.43^{\prime} \mathrm{S}, 19^{\circ} 38.62^{\prime} \mathrm{W}$, Austasen, Antarctica, 596.4-597.6 m depth, 31 December 2003, one colony without holdfast.

Description of the holotype

Bottlebrush colony (Fig. 11a) of $66 \mathrm{~cm}$ in height and $5.5 \mathrm{~cm}$ in width, main stem without lateral branches. First $9 \mathrm{~cm}$ of the main stem without branchlets, on the remain main stem branchlets all around, up to $4.5 \mathrm{~cm}$ long, simple at basal portion or after the first $5 \mathrm{~mm}$ ramified up to fourth order (usually 2, exceptionally 3 terminal branchlets starting from the same point), terminal branchlets up to $3.5 \mathrm{~cm}$ long (Fig. 11b). Axis light brown in colour, stiff and firmly attached to a rock by a greyish, calcareous, discoidal holdfast of $1.3 \mathrm{~cm}$ diameter, basal axis diameter of $3 \mathrm{~mm}$.

Polyps appressed to main stem and branchlets (Fig. 12c), directed upward, arranged singly, apparently alternate to loosely spiral, 11-18 polyps per $\mathrm{cm}$. Polyps (Fig. 12) small, cone shaped; about $0.71-0.96 \mathrm{~mm}$ in height and 0.31-0.44 mm in width at marginal scale level. Polyp body with 5 longitudinal rows of scales, 3-4 scales (excluding operculars) on each longitudinal abaxial row (Fig. 12a, b) overlapping one another.

Opercular scales (Fig. 13a) eight in number, small, 0.25$0.43 \mathrm{~mm} \times 0.07-0.16 \mathrm{~mm}$, isosceles shaped or spoon shaped, adaxial scales reduced. Proximal inner surface slightly tuberculate, covering less than half of the length (about 2/3 of the basal part), with an apical serrated spine as a continuation of well-developed keel. Outer surface quite smooth. Basal margin with digitate processes, with tendency to square shape, free margin strongly serrated.

Marginal scales (Fig. 13b) in numbers of eight, small, $0.21-0.28 \mathrm{~mm} \times 0.16-0.23 \mathrm{~mm}$, round to rhomboidal shaped, adaxials reduced. Proximal inner surface tuberculate, covering up to about $75 \%$ of their longitude. Distal inner surface smooth, with prominent keel projecting to form a short spine distally. Outer surface smooth. Basal margin with digitate processes, free margin serrated.

Body scales (Fig. 13c) circular shaped, like marginal scales in size, $0.22-0.28 \mathrm{~mm}$ in maximum length, without keel or spine. Adaxials with tendency to be reduced. Inner surface tuberculate, outer surface smooth. Free margin quite entire, basal margin irregular due to the presence of tubercles and processes.

Coenenchymal scales (Fig. 13d) round to oval shaped, $0.12-0.22 \mathrm{~mm}$ in maximum diameter. Inner surface sparsely tuberculate, outer surface smooth with some granules or short ridges. Irregular margin due to the presence of tubercles and serrations. 
Variability

The general colonial structure of the paratypes and additional examined material are quite similar to that of the holotype. The material studied includes colonies from 11 to $66 \mathrm{~cm}$ in height. The branchlets arise from all around the main stem; some colonies have bend branchlets, giving a false impression of a flattened or pinnate forms, some branchlets are bent upward, up to $4.5 \mathrm{~cm}$ in length, simple or ramified, like those of the holotype. The polyp's proximity to the stem varies from inclined to appressed. There are from 10 to 18 polyps per centimetre on branchlets, and they are up to about $1.1 \mathrm{~mm}$ in height. The distribution and shape of the sclerites of the polyps and coenenchyme are as in the holotype.

Geographic and bathymetrical distribution

At present, Thouarella minuta sp. nov. is known only from, Austasen, Antarctica (Fig. 1), between 226 and $338 \mathrm{~m}$ in depth.

\section{Etymology}

In this species, the most interesting character is the minute size of the polyps, one of the smallest in comparison with its congeners. The specific name, minuta, comes from Latin, meaning small or minute.

\section{Remarks}

We include Thouarella minuta sp. nov. in the subgenus Thouarella due to the presence of a spine on the marginal scales and the single arrangement of the polyps on the branchlets. Five species in this group are comparable to $T$. minuta sp. nov. because of the presence of polyps with 4-5 scales in the longitudinal abaxial rows: $T$. variabilis Wright and Studer, 1889, T. brucei Thomson and Ritchie, 1906, T. striata Kükenthal, 1907, T. clavata Kükenthal, 1908, and $T$. pendulina Roule, 1908.

Thouarella striata differs from all other species listed above due to the distinct radial ridges on the outer surface of the polyp scales (Kükenthal 1907); quite different from the smooth surface of the sclerites in T. minuta sp. nov. In addition, polyps of $T$. striata are $1.5-2 \mathrm{~mm}$ in height, while those of $T$. minuta sp. nov. only reach $1.1 \mathrm{~mm}$ (usually less).

Thouarella clavata and Thouarella variabilis show polyps larger than $1.5 \mathrm{~mm}$ in height, the former reaching $2 \mathrm{~mm}$ and the latter usually larger than $2 \mathrm{~mm}$ (see Kükenthal 1907; Wright and Studer 1889). This feature clearly contrasts with the polyps of T. minuta sp. nov. All varieties of $T$. variabilis considered by Wright and Studer
(1889: 68) have more or less well-developed distal spines on the "ultimate and penultimate rows", and those authors mention that var. gracilis also has a median keel on the "uppermost" scales. For T. clavata, Kükenthal (1907 as T. aff. antarctica, 1908) commented that the operculars have keels, and the marginals have spines; while in T. minuta sp. nov., both the operculars and the marginals show spines and keels, the spine of the marginals being shorter.

Thouarella pendulina and Thouarella brucei (taking into account the scarce and sometimes imprecise original description of this latter species) show polyps of about $1 \mathrm{~mm}$ (up to $1.5 \mathrm{~mm}$ in the former) (see Thomson and Ritchie 1906; Roule 1908; Gravier 1914). As previously described, $T$. minuta sp. nov. has polyps ranging between 0.7 and $1.1 \mathrm{~mm}$ in height. Thouarella pendulina is clearly distinguishable from the other two species by the dense distribution of polyps in the branchlets, up to 70 polyps per $1 \mathrm{~cm}$. Although T. pendulina and T. minuta sp. nov. share a characteristic smooth outer surface of the scales, the submarginal scales of $T$. pendulina bear a small spine (after the drawing in Gravier (1914): fig. 90, these scales apparently have a keel), not present in T. minuta sp. nov.

Apart from the few characters mentioned here and repetitively included in the available key to species of Thouarella (Kükenthal 1924), the original description of $T$. brucei does not offer reliable diagnostic characteristics that could be used here in this species comparison. Kükenthal (1919) commented on the incomplete description of this species, especially on the description of the polyps and the designation of distalmost scale cycles, maintaining this species in the subgenus Parathouarella (currently reconsidered as subgenus Thouarella). Later on, Kukenthal (1924: 301) included this species as dubiae atque incertae sedis. The original material came from shelf depths of three widely separated localities [Burdwood Bank $\left(\sim 54^{\circ} \mathrm{S}\right)$, Gough Island $\left(\sim 40^{\circ} \mathrm{S}\right)$ and Santa Helena $\left(\sim 16^{\circ} \mathrm{S}\right.$, depth not mentioned)], although the type is that from Burwood Bank (Emma Sherlock, personnel communication). Broch (1965) described the morphology of several specimens collected at Burdwood Bank from about $111 \mathrm{~m}$ depths and assigned his material to the Thomson and Ritchie' species. However, the material examined by Broch clearly differs from that described by the original authors in the arrangement of polyps: "The polyps are placed in distinct whorls on the twigs,... The whorl generally consists of 3 or 4 polyps, but in the distal part of more luxuriantly developed twigs whorls with 5 polyps also are rather common" (see Broch 1965: 27), compared to "On the twigs they [the polyps] are closely approximated, arising in all directions and without any definite arrangement" (see Thomson and Ritchie 1906: 853). Despite the few characters available for T. brucei, this species has lateral branches from the main stem, and the branchlets are proportionally shorter and less 
ramified in comparison with those in $T$. minuta sp. nov. (see Thomson and Ritchie 1906: pl. I, fig. 1 and Fig. 11b of this paper), while the numerous colonies examined of the new taxon show only elongated colonies without lateral branches (see Fig. 11a).

Acknowledgments The authors thank Dr. R. van Soest and E.J. Beglinger (Universiteit van Amsterdam), Bernhard Ruthensteiner and Eva Lodde (Zoologische Staatssammlung München) for lending the specimens of Thouarella laxa and T. tydemani for examination and Emma Sherlock (NHM in London) for information about the type material of T. brucei. We also acknowledge the valuable assistance of the officers and crew of the R/V Polarstern and many colleagues on board during the EASIZ III, LAMPOS and BENDEX cruises. We extend our thanks to the cruise leaders and steering committee of the cruises especially Wolf E. Arntz (Alfred Wegener Institut, Bremerhaven), who kindly facilitated the work on board and for the opportunity to collaborate in these Antarctic programmes. Special thanks are addressed to some friends and colleagues for their valuable assistance during EASIZ III ( ${ }^{\mathrm{a}}$ Isabel Alfonso, Josep-Maria Gili), LAMPOS (Neus Vert and Estefanía Rodríguez) and BENDEX (Estefanía Rodríguez, Josep-Maria Gili) cruises. Support for this work was provided by the Spanish CICYT projects ANT98-1739-E and ANT99-1608-E (EASIZ III), REN2001-4929-E/ANT (LAMPOS), REN2003-04236 (BENDEX) and POL2006-06399/CGL (CLIMANT). Mr. Tony Krupa is thanked for reviewing the English version.

\section{References}

Alderslade P (1998) Revisionary systematics in the gorgonian family Isididae, with description of numerous new taxa (Coelenterata, Octocorallia). Rec West Aust Mus 55:1-359

Bayer FM (1980) Armadillogorgia cyathella and Ophidiogorgia paradoxa, two new genera and species of primnoid octocorals (Coelenterata: Anthozoa) from South Georgia and South Orkney Islands. Proc Biol Soc Wash 93(1):216-228

Bayer FM (1981) Key to the genera of Octocorallia exclusive of Pennatulacea (Coelenterata: Anthozoa), with diagnoses of new taxa. Proc Biol Soc Wash 94(3):901-947

Bayer FM (1988) Mirostenella articulata, a remarkable new genus and species of primnoid octocoral with uncalcified axial nodes. Proc Biol Soc Wash 101(2):251-256 (figs. 1-3)

Bayer FM (1996a) The Antarctic genus Callozostron and its relationship to Primnoella (Octocorallia: Gogonacea: Primnoidae). Proc Biol Soc Wash 109(1):150-203

Bayer FM (1996b) New Primnoid Gorgonians (Coelenterata:Octocorallia) from Antarctic waters. Bull Mar Sci 58(2):511-530

Bayer FM (1998) A review of the circumaustral gorgonacean genus Fannyella Gray, 1870 with description of five new species
(Coelenterata: Octocorallia: Primnoidae). Senckenberg Biol 77(2):161-204

Bayer FM, Stefani J (1988) Primnoidae (Gorgonacea) de NouvelleCalédonie. Bull Mus Natn Hist Nat Paris 10(A)(3):449-476

Bayer FM, Grasshoff M, Verseveldt J (1983) Illustrated trilingual glossary of morphological and anatomical terms applied to Octocorallia. E.J. Brill/Dr. W. Backhuys, Leiden, pp 1-75

Broch H (1965) Some octocorals from Antarctic waters. Scientific results of the "Brategg" expedition, 1947-48. Christensens Hvalfangstmuseum i Sandejford Publikasjon 26:19-38 1-7

Cairns SD (2006) Studies on western Atlantic Octocorallia (Coelenterata: Anthozoa). Part 6: the genera Primnoella Gray, 1858; Thouarella Gray, 1870; Dasystenella Versluys, 1906. Proc Biol Soc Wash 119(2):161-194

Cairns SD, Bayer FM (2009) A generic revision and phylogenetic analysis of the Primnoidae (Cnidaria: Octocorallia). Smithson Contrib Zool 629:1-79

Gravier CH (1914) Alcyonaires. Deuxième Expédition Antarctique Française (1908-1910). Sciences Naturelles: Documents scientifiques, pp 1-118, 1-10

Gray JE (1858) Synopsis of the families and genera of Axiferous zoophytes or barked corals. Proc Zool Soc Lond 1857:278-294

Gray JE (1870) Catalogue of the lithophytes or stony corals in the collection of the British Museum. British Museum, London, pp 1-51

Kinoshita K (1908) Diplocalyptra, eine neue Untergattung von Thouarella (Primnoidae). Annot Zool Jap 7(1):49-60

Kükenthal W (1907) Gorgoniden der Deustchen Tiefsee Expedition. Zool Anz 31(7):202-212

Kükenthal W (1908) Diagnosen neuer Gorgoniden (4 Mitteilung). Zool Anz 33(1):9-20

Kükenthal W (1915) System und Stammesgeshichte der Primnoidae. Zool Anz 46(5):142-158

Kükenthal W (1919) Gorgonaria. Wissensch Ergebn deutschen Tiefsee-Exped "Valdivia" 13(2):1-946 30-89

Kükenthal W (1924) Coelenterata: Gorgonaria. Das Tierreich 47. Walter de Gruyter and Co, Berlin, pp 1-478

Kükenthal W, Gorzawsky H (1908) Diagnosen neuer japanischer Gorgoniden (Reise Doflein 1904-1905). Zool Anz 32:621-631

López-González PJ, Gili JM (2002) A new primnoid genus (Anthozoa: Octocorallia) from the Southern Ocean. Sci Mar 66(4):383397

Roule L (1908) Alcyonaires. Expédition Antarctique Française (1903-1905). Sciencies Naturelles: Documents scientifiques 15:1-6 (1)

Thomson JA, Ritchie J (1906) The Alcyonarians of the Scottisch National Antarctic Expedition. Trans $\mathrm{R}$ Soc Edinburgh 41(3):851-860 (1-2)

Versluys J (1906) Die Gorgoniden der Siboga-Expedition. II. Die Primnoidae. Siboga-Expeditie 13a:1-187

Wright EP, Studer T (1889) Report on the Alcyonaria collected by H.M.S. Challenger during the years 1873-1876. Rep Sci Res Chall Zool 31:i-lxxvii 1-314, 1-43 